\title{
Osteoid Osteoma in the Fourth Metatarsal: A Previously Undescribed Cause of Forefoot Pain
}

\section{Kinghorn $\mathbf{A F}^{*}$, Afinowi R, Sharpe $\mathrm{J}$ and Farndon $\mathbf{M}$}

Harrogate District Hospital, Harrogate, North Yorkshire, UK

"Corresponding author: Alison Kinghorn, Core Surgical Trainee Year 2, Harrogate District Hospital, Trauma and Orthopaedics, Lancaster Park Road, Harrogate, North Yorkshire, HG2 7SX, UK, Tel: +447905 827695; E-mail: afkinghorn@gmail.com

Received date: Feb 16, 2015, Accepted date: Mar 12, 2015, Publication date: Mar 16, 2015

Copyright: (c) 2015 Kinghorn AF, et al. This is an open-access article distributed under the terms of the Creative Commons Attribution License, which permits unrestricted use, distribution, and reproduction in any medium, provided the original author and source are credited.

\begin{abstract}
We present the case of a 26 year old man who reported persistent pain in his left foot. He had been troubled by this pain for six years but despite previous consultation and investigation the cause of his symptoms had remained elusive.

A magnetic resonance imaging (MRI) scan was performed which hinted at a small area of oedema in the head of the fourth metatarsal. Based on these findings, and working in close conjunction with our specialist radiology colleagues, a CT scan with finer slices was able to identify a $3 \mathrm{~mm}$ diameter lucency with a sclerotic central nidus.

Following this challenging diagnosis, the preferred management option was an open resection of the lesion, due to its small size and superficial position. The macro and microscopic appearances of the excised lesion supported the diagnosis of osteoid osteoma, as did the complete resolution of the patient's symptoms following removal of the offending lesion.

We believe this to be the first case of an isolated osteoid osteoma in the fourth metatarsal ever described in the orthopaedic literature. It highlights the importance of pursuing a diagnosis with the aid of multiple imaging modalities and MRI has again proved its use in the resolution of orthopaedic clinical conundrums.
\end{abstract}

Keywords: Osteoid osteoma; Magnetic resonance imaging; Foot; Pain; Orthopaedics; Bone tumour

\section{Case Report}

A previously fit and well 26 year old man attended the orthopaedic clinic complaining of persistent pain in his left foot. These symptoms had been a constant source of discomfort for the past six years but despite previous consultations whilst resident in another city, the diagnosis had remained elusive and the pain had not abated. The patient felt that the pain was worst first thing in the morning but was also frequently awoken with pain during the night. The pain was present at rest and not worsened by any particular movement. In addition he felt that alcohol and/or salty food exacerbated the pain. Normally an active man, his foot pain had been preventing him from running although he was able to continue cycling and gym work. He recalled a fracture in this foot when aged thirteen, but was unable to identify any traumatic incident which coincided with the onset of symptoms.

On close questioning and clinical examination the pain appeared to centred on the dorsal aspect of the 4 th metatarsal head. There were no signs of neurological or vascular compromise but there was a degree of planovalgus as well as marked stiffness of his left hindfoot. Previous investigations had included plain radiographs (Figure 1) and an ultrasound; both of which had been inconclusive.
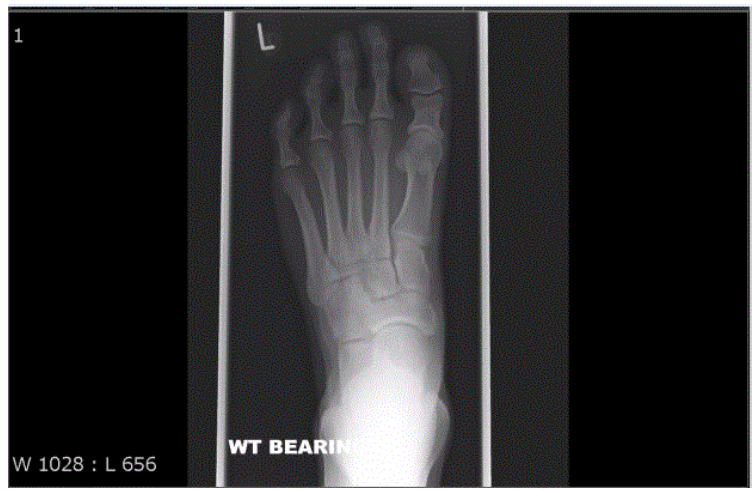

Figure 1: Plain AP radiograph of the left foot showing no visible abnormality.

In view of the obvious diagnostic challenge, the options for the most suitable next investigation were discussed with a specialist musculoskeletal radiologist. Magnetic resonance imaging (MRI) was suggested as the preferred initial modality to investigate undiagnosed, severe, bony pain. This hinted at a small area of oedema in the head of the fourth metatarsal which correlated closely with the origin of the pain (Figure 2). Now a defined location of abnormality had been identified, it was examined in more detail with a fine slice computer tomography (CT) scan. 
Citation: Kinghorn AF, Afinowi R, Sharpe J, Farndon M (2015) Osteoid Osteoma in the Fourth Metatarsal: A Previously Undescribed Cause of

This identified $3 \mathrm{~mm}$ diameter lucency with a sclerotic central nidus (Figure 3). Without the localising ability of the MRI, the lesion would have been almost impossible to identify on CT alone. In the opinion of the specialist radiologist, when taken in conjunction with the MRI findings and patient symptoms, the lesion was consistent with a small osteoid osteoma.

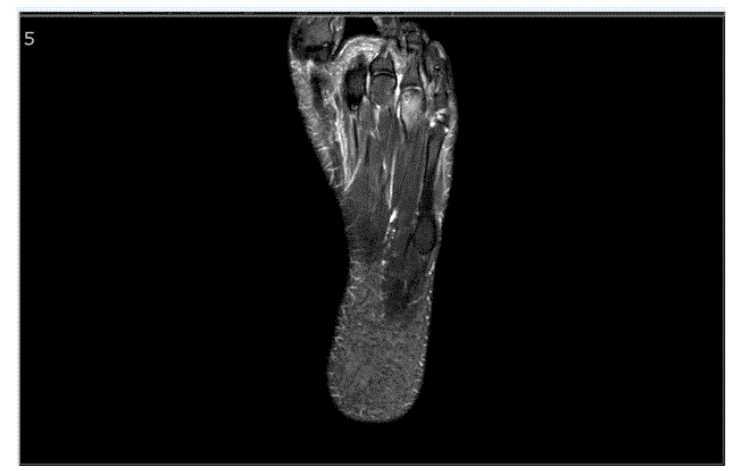

Figure 2: STIR MRI (axial) highlighting a small lesion in the head of the fourth metatarsal surrounded by oedema.

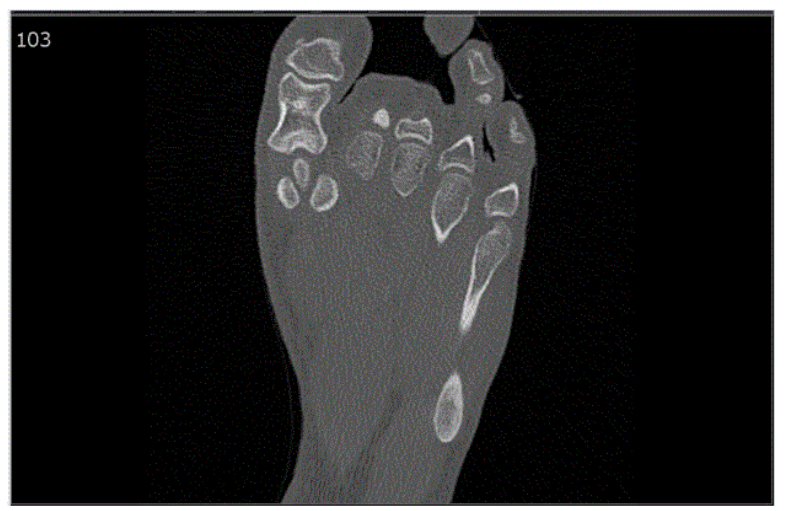

Figure 3: CT (axial) showing the fourth metatarsal lesion.

Having achieved a likely diagnosis, the management options were considered. The three leading options were open resection, arthroscopic resection or radiofrequency/cryoablation. The latter option was discounted as the lesion was located very close to the tarsometatarsal joint and as such, either ablation modality would risk damage to the chondral surface. Due to the dimensions of the joint involved, it was felt that arthroscopic resection would be equally unsuitable.

However, the small size and superficial position of the lesion favoured an open resection and this was performed without incident under an ankle block. The chondral surface appeared normal despite a mild synovitis, but under a thickened area of periosteum a $3 \mathrm{~mm}$ reddish cortical lesion was identified behind the medial head (Figure 4). This was excised and sent for histological analysis. No filling of the defect or internal fixation was required.

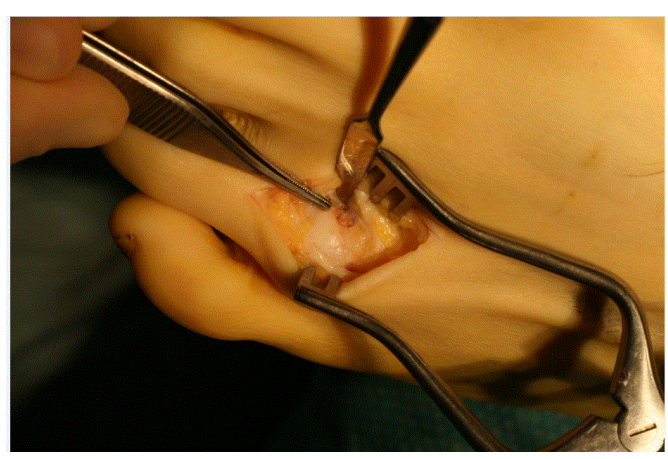

Figure 4: Intraoperative photograph displaying the small but well defined, red, cortical lesion.

The histopathology report described an decalcified area comprising fragments of mature bone together with irregular osteoid trabecular, some of which showed focal osteoblastic rimming. The appearances were in keeping with the clinical impression of osteoid osteoma with the areas of osteoid representing the central nidus (Figure 5).

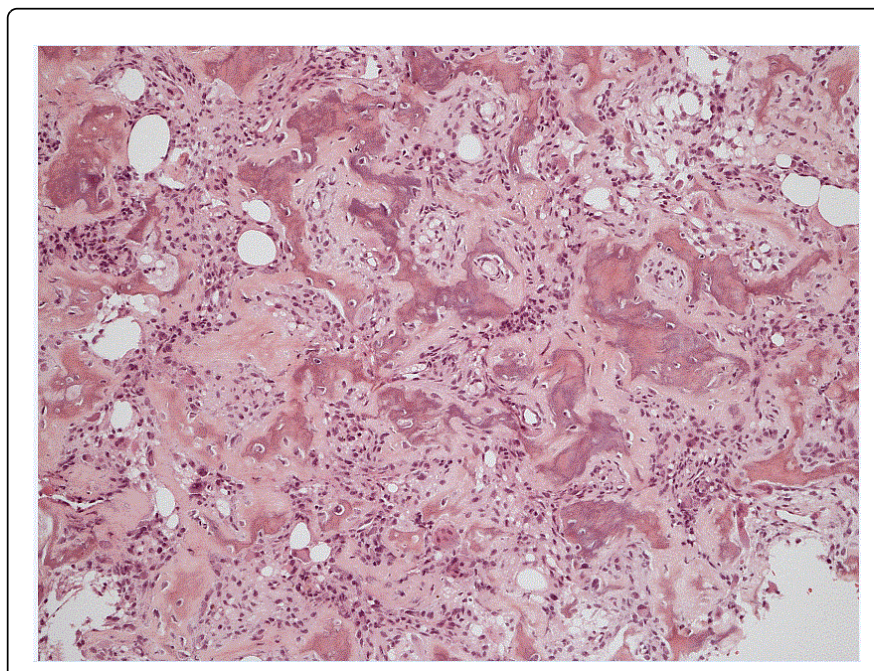

Figure 5: Histological slides of the characteristic central nidus.

The final confirmation of the diagnosis came with the success of the surgical treatment. Following resection of the offending lesion, the patient's pain completely resolved.

\section{Discussion}

Osteoid osteomas are small, benign, bone tumours (less than $1 \mathrm{~cm}$ diameter) which typically engender symptoms greatly out of proportion to the size of the lesion [1]. First described in 1935 [2], those affected are generally young adults and are twice as likely to be male than female [3]. Of all cases of osteoid osteoma it is estimated that between $2 \%$ and $11 \%$ occur in the foot (most commonly in the talus) [3,4], though this still makes it the most frequent benign tumour affecting the foot. Incidence in the metatarsals is particularly rare with 
Page 3 of 3

very few published cases $[2,4-11]$, none of which describe isolated lesions in the fourth metatarsal.

The history given by our patient is not unusual and osteoid osteomas are often difficult to diagnose, particularly when they occur in unusual locations, due to their small size and vague symptoms. Up to a third of patients may relate a history of trauma in a retrospective attempt to explain their pain [2]. This has the unfortunate result of confounding the diagnosis and delaying management. As in this case, the classic symptom of dramatic pain relief with salicylates is not universally present [1].

Different case reports make different analyses of the advantages of MRI versus CT scanning. Fine slice CT is the imaging modality of choice for some as it $[2,4]$ allows the level of resolution and detail to pick out the characteristic pattern of a central sclerotic nidus with surrounding lucency. However, MRI is often a helpful aid to diagnosis as in cases such as this, it identifies to location of an abnormality $[3,4,11]$. The findings of MRI may be non-specific, and some suggest that it can steer clinicians erroneously towards a malignant or infective process due to the surrounding bone oedema $[2,4]$. In a case such as this, MRI certainly proved its place in the explanation of undiagnosed foot pain. The MRI findings, in conjunction with the close cooperation between orthopaedic and radiological specialists regarding the clinical findings, allowed the CT scan and radiologist to focus on the precise area and fully define the characteristics of the lesion. The only way to be fully assured of the diagnosis however is by histological analysis.

As mentioned in the case report, there are three main options for those patients requiring surgical treatment. The choice between resection (open or arthroscopic) and ablation (radiofrequency or thermal) is often decided, as in this case, by the location of the lesion. Larger lesions may also necessitate an open technique if the resection is likely to threaten the structural integrity of the bone and prophylactic internal fixation is required (in the femoral neck for example) [1]. Symptoms are likely to recur unless the nidus is completely removed or destroyed and as such, intraoperative radiological guidance or use of tetracycline fluorescence can be of assistance [4]. The results from the non-invasive techniques are comparable with surgical resection but come with the disadvantage of precluding histological diagnosis $[4,12]$.

\section{Conclusion}

We believe this to be the first case of an isolated osteoid osteoma in the fourth metatarsal ever described in the orthopaedic literature. It highlights the necessity of combining multiple imaging modalities, with MRI proving its use in the resolution of orthopaedic clinical conundrums. In addition this case shows the critical importance of the multidisciplinary team in pursuing an elusive diagnosis.

\section{References}

1. Solomon L, Warwick DJ, Nayagam S (2010) Apley's System of Orthopaedics and Fractures. 9th Ed. Hodder Arnold, London.

2. Spencer E, Beirman JS, Femino JE (2002) Osteoid osteoma of the fifth metatarsal: a case report and literature review. Foot and Ankle Surg. 8: 71-78.

3. Le Corroller T, Champsaur P (2011) Osteoid osteoma of the midfoot: percutaneous radiofrequency treatment in 2 cases. J Foot Ankle Surg 50: 754-757.

4. Asunción J, Torrent J, González C, Poggio D (2013) Intra-articular osteoid osteoma of the first metatarsal. Foot Ankle Int 34: 448-454.

5. Freschi S, Dodson NB (2007) Osteoid osteoma: an uncommon cause of foot pain. J Am Podiatr Med Assoc 97: 405-409.

6. Georgoulis AD, Soucacos PN, Beris AE, Xenakis TA (1995) Osteoid osteoma in the differential diagnosis of persistent joint pain. Knee Surg Sports Traumatol Arthrosc 3: 125-128.

7. O'Connell JX, Rosenthal DI, Mankin HJ, Gudger GK, Dickersin GR, et al. (1993) A unique multifocal osteoblastoma-like tumor of the bones of a single lower extremity. Report of a case. J Bone Joint Surg Am 75: 597-602.

8. Massari L, Colamussi P, Brandolini F, Iirillo A (1998) Osteoid osteoma at the base of the second metatarsal bone: case report. Foot and Ankle Surgery 4: 83-86.

9. Albagali M, Mohammed H, Salloom F, Hussain M (2009) Osteoid Osteoma of the Fifth Metatarsal Bone. Bahrain Med Bull 31: 3.

10. Mahdinasab S (2006) A case report of osteoid esteem of the 5th metatarsal bone. Jundishapur Sci Med Journ 3: 647-50.

11. Szendroi M, Köllo K, Antal I, Lakatos J, Szoke G (2004) Intraarticular osteoid osteoma: clinical features, imaging results, and comparison with extraarticular localization. J Rheumatol 31: 957-964.

12. Lee EH, Shafi M, Hui JH (2006) Osteoid osteoma: a current review. J Pediatr Orthop 26: 695-700. 